\title{
Tlx3 and Runx1 Act in Combination to Coordinate the Development of a Cohort of Nociceptors, Thermoceptors, and Pruriceptors
}

\author{
Claudia Lopes, ${ }^{1,2 *}$ Zijing Liu, ${ }^{1 *}$ Yi Xu, ${ }^{1 *}$ and Qiufu $\mathrm{Ma}^{1}$ \\ ${ }^{1}$ Dana-Farber Cancer Institute and Department of Neurobiology, Harvard Medical School, Boston, Massachusetts 02115, and ${ }^{2}$ Laboratory of Molecular Cell \\ Biology, University of Porto, 4200-319 Porto, Portugal
}

\begin{abstract}
Neurons in the mouse dorsal root ganglia (DRGs) are composed of a variety of sensory modalities, such as pain-related nociceptors, itch-related pruriceptors, and thermoceptors. All these neurons are derived from late-born neurons that are initially marked by the expression of the nerve growth factor receptor TrkA. During perinatal and postnatal development, these TrkA lineage neurons are globally segregated into Ret-expressing and TrkA-expressing subtypes, and start to express a variety of sensory receptors and ion channels. The runt domain transcription factor Runx1 plays a pivotal role in controlling these developmental processes, but it remains unclear how it works. Here we showed that the homeodomain transcription factor Tlx3, expressed broadly in DRG neurons, is required to establish most Runx1-dependent phenotypes, including the segregation of TrkA-expressing versus Ret-expressing neurons and the expression of a dozen of sensory channels and receptors implicated in sensing pain, itch and temperature. Expression of Runx1 and Tlx 3 is independent of each other at prenatal stages when they first establish the expression of these channels and receptors. Moreover, overexpression of Runx 1 plus Tlx 3 was able to induce ectopic expression of sensory channels and receptors. Collectively, these studies suggest that genetically Tlx 3 acts in combination with Runx1 to control the development of a cohort of nociceptors, thermoceptors, and pruriceptors in mice.
\end{abstract}

\section{Introduction}

Neurons in the DRGs involved in sensing pain, itch, and temperature are derived from embryonic neurons initially marked by the expression of TrkA, the nerve growth factor receptor (Liu and Ma, 2011; Lallemend and Ernfors, 2012). For simplicity, "TrkA lineage neurons" are used here to include all sensory neurons initially expressing TrkA. In the past decade, a number of transcription factors have been identified that control distinct aspects of TrkA lineage neuron development (Liu and Ma, 2011; Lallemend and Ernfors, 2012). Genesis of TrkA lineage neurons is dependent mainly on the proneural protein Neurog1, but also partly on Neurog2 in caudal DRGs (Ma et al., 1998, 1999; Bachy et al., 2011). The homeodomain proteins Brn3a and Islet1 are critical for making the transition from neurogenesis to neuronal

Received March 6, 2012; revised May 1, 2012; accepted May 28, 2012.

Author contributions: C.L., Z.L., Y.X., and Q.M. designed research;C.L., Z.L., and Y.X. performed research; C.L., Z.L., Y.X., and Q.M. analyzed data; C.L., Z.L., and Q.M. wrote the paper.

We thank Drs. Nancy Speck and Gary Gilliland for the Runx1 conditional knock-out mice, Rohini Kuner for the Nav1.8-Cre mice, and David Rowitch for the Wnt1-Cre mice. We also thank Dr. Carmen Birchmeier, Tom Jessell, and Louis Reichardt for the Tlx3, Runx1, and TrkA antibodies, respectively. We also thank the Mouse Gene Manipulation Facility of the Children's Hospital Intellectual and Developmental Disabilities Research Center (IDDRC) supported by NIH Grant P30-HD18655. The work done in the Ma lab was supported by NIH grants from NIDCR (1R01DE018025) and NINDS (P01NS047572).

${ }^{*}$ C.L., Z.L., and Y.X. contributed equally to this article.

Z. Liu's present address: Beijing Institute of Biotechnology, 27 Tai-Ping Road, Beijing 100850, China.

Correspondence should be addressed to Qiufu Ma, Dana-Farber Cancer Institute and Department of Neurobiology, Harvard Medical School, 450 Brookline Avenue, Boston, MA 02115. E-mail: Qiufu_Ma@dfci.harvard.edu.

DOI:10.1523/JNEUROSCI.1109-12.2012

Copyright $\odot 2012$ the authors $\quad 0270-6474 / 12 / 329706-10 \$ 15.00 / 0$ differentiation, and they also control sensory neuron identities (Eng et al., 2004; Sun et al., 2008; Lanier et al., 2009; Dykes et al., 2010, 2011; Zou et al., 2012). The zinfic protein KLF7 acts synergistically with Brn3a to control TrkA expression (Lei et al., 2006). The homeobox protein Cux2 might be involved with the development of the thinly myelinated A- $\delta$ subset of TrkA lineage sensory neurons (Bachy et al., 2011).

The runt domain protein Runx1 also plays pivotal roles in controlling TrkA lineage neuron development (Liu and Ma, 2011). Runxl is initially expressed in most newly born TrkA-expressing cells, and both Runx1 and TrkA expression then undergoes dynamic changes during perinatal and postnatal development (Liu and Ma, 2011; Lallemend and Ernfors, 2012). Runxl is required for proper development of $\sim 50 \%$ of those TrkA lineage neurons that are going to switch off TrkA and activate the Ret receptor tyrosine kinase (Chen et al., 2006; Yoshikawa et al., 2007). Conversely, the other $50 \%$ of TrkA lineage neurons retain TrkA and switch off Runx1, most of which become peptidergic neurons marked by the expression of the calcitonin gene-related peptide (CGRP) and substance P (SP) (Chen et al., 2006). A subset of Runx1-dependent neurons are also peptidergic (Liu and Ma, 2011; Lallemend and Ernfors, 2012). In mice with a conditional knock-out of Runx1 in sensory precursors, Ret ${ }^{+}$sensory neurons switch to become $\operatorname{TrkA}^{+}$neurons (Chen et al., 2006; Yoshikawa et al., 2007). Within $\operatorname{Ret}^{+}$sublineage neurons, Runx1 is necessary for the expression of dozens of channels and receptors involved in sensing pain, itch, and/or temperature (Chen et al., 2006; Abdel Samad et al., 2010; Liu and Ma, 2011). 
However, it remains unclear how Runxl coordinates such diverse phenotypes within the Ret $^{+}$subset of TrkA lineage neurons. The homeodomain protein Tlx3 plays a pivotal role in controlling relay somatic sensory neuron development in the dorsal spinal cord and hindbrain (Qian et al., 2002; Cheng et al., 2004; Li et al., 2006; Xu et al., 2008). Here, we report that in DRG neurons, $T l \times 3$ is required to establish most Runx1-dependent sensory phenotypes, and Runx1 and Tlx3 operate at different developmental stages to establish distinct sensory modalities.

\section{Materials and Methods}

Animals. The generation and genotyping of Tlx3 complete null mice, Runx1 conditional knock-out mice, Wnt1-Cre mice, and Nav1.8-Cre mice have been previously described (Danielian et al., 1998; Shirasawa et al., 2000; Qian et al., 2001; Agarwal et al., 2004; Growney et al., 2005; Chen et al., 2006). Male and female embryos and mice were equally used for the analyses. The morning the vaginal plugs were observed was considered as embryonic day 0.5 (E0.5). All animal procedures are within protocols reviewed and approved by the Animal Care Committees at the Dana Farber Cancer Institute, Harvard Medical School.

Generation of Tlx3 conditional null mice. Schematics in Figure 2 (see below) illustrate our strategy to generate mice carrying a conditional null allele of $T l \times 3$. The targeting vector was constructed partly by using the recombination system developed by Liu et al. (2003). The 5' LoxP DNA sequence (the recognition site for the Cre recombinase) was inserted into the first intron at the site $0.135 \mathrm{~kb} 5^{\prime}$ to the second exon; a EcoRV site was added 5 ' to this LoxP site, which was used for identification of embryonic stem cell clones with successful gene targeting (see Fig. 2). The FRT-NeoFRT-LoxP positive selection cassette, which drives the expression of the aminoglycoside phosphotransferase that will confer G418 resistant, was inserted into the second intron at $0.3 \mathrm{~kb} 3^{\prime}$ to the second exon. This neo cassette is flanked with two FRT sites, which can be recognized and cleaved by the Flipase recombinase (Flpe), and ends with the second LoxP site at the $3^{\prime}$ end. The $9.4 \mathrm{~kb} 5^{\prime}$ recombination arm starts at the endogenous EcoR1 site at the $5^{\prime}$ end and ends right next to the first Loxp site $\left(0.235 \mathrm{~kb} 3^{\prime}\right.$ to the first exon). The $3.1 \mathrm{~kb} 3^{\prime}$ recombination arm starts right after the neo cassette $\left(0.3 \mathrm{~kb} 3^{\prime}\right.$ to the second exon) and ends with the endogenous Sal1 site (see Fig. 2). The DTA cassette, which drives the expression of the Diphtheria Toxin A (DTA) for negative selection, is placed 3' to the short recombination arm (see Fig. 2). Upon linearization, this targeting vector was electroporated into the J1 embryonic stem (ES) cell line (derived from 129Sv/J mouse strain), with G418 included in the culture medium for positive selection. Southern hybridization on genomic DNA was performed, using a 0.889 Sall-Xholl genomic fragment ( $3^{\prime}$ to the short recombination arm; see Fig. 2) as the probe, which produced a $15.3 \mathrm{~kb}$ EcoRV fragment for the wild-type allele, and a $10.5 \mathrm{~kb}$ fragment for the targeted allele (see Fig. 2). Greater than $80 \%$ of ES clones showed successful targeting, and the targeted ES cells were injected into the blastocysts derived from C57BL/6J females. Chimeric male mice were mated with C57BL/6J females to generate heterozygous mice carrying the targeted allele. These mice were mated with the Flpe deleter mouse line (Rodríguez et al., 2000), to remove the neo cassette, leading to the creation of the mice carrying the $T l \times 3$ floxed allele, referred to as $T l x 3^{F}$ (see Fig. 2). $T l \times 3^{F}$ mice were then mated with Nav1.8-Cre mice to remove the second exon, leading to the creation of the null allele and generation of conditional knock-out mice $\left(T 7 x 3^{F / F}\right.$; Nav1. $8^{\mathrm{Cre} /+}$ ) (see Fig. 2). The genotyping for the conditional knock-out mice after crossing $T l x 3^{F / F}$ mice with Nav1.8-Cre mice was performed with the following set of primers: (1) for Nav1.8-Cre allele, 5-AGACTAATCGCCAT CTTCCAGC-3 and 5'-TATCTCACGTACTGACGGTG-3', and (2) for Tl $\times 3$ wild-type and floxed allele, $5^{\prime}$-TGTTTCGCCTCCTTTGCTCG- $3^{\prime}$ and $5^{\prime}$-GTTGGATGGAAGCAAAGATAG-3', with the floxed allele showing a larger DNA band after gel electrophoresis.

In situ hybridization and immunostaining. In situ hybridization and the probes used in this study (Mrgprd, Mrgpra3, Mrgprb4, Mrgprb5, TRPA1, TRPM8, TRPV1, Nav1.9, Ret, P2X3, Runx1, Tlx3) have been described previously (Ma et al., 1999; Qian et al., 2001; Chen et al., 2006; Liu et al., 2008; Abdel Samad et al., 2010). Collection of E16.5 and postnatal day 0 (P0) embryos was done in ice-cold PBS, fixed overnight in $4 \%$ paraformaldehyde in PBS (PFA-PBS), and saturated in 20\% sucrose in PBS, also overnight at $4^{\circ} \mathrm{C}$. For P30 mice, after perfusion with $4 \%$ PFAPBS, lumbar and thoracic DRGs were dissected and continued to be fixed in $4 \%$ PFA-PBS for $2 \mathrm{~h}$ and saturated in $20 \%$ sucrose overnight at $4^{\circ} \mathrm{C}$. For immunohistochemistry studies, the following antibodies were used: rabbit and guinea pig anti-Tlx3 (a gift from C. Birchmeier, Max Delbrück Center for Molecular Medicine, Berlin, Germany), rabbit anti-Runx1 (a gift from T. Jessell, Columbia University, New York, NY), P2X3 (1:1000, Neuromics), IB4-biotin (10 $\mu \mathrm{g} / \mathrm{ml}$, Sigma), rabbit anti-CGRP (1:500, Peninsula), and rabbit anti-TrkA (1:500, a gift from L. Reichardt, University of California, San Francisco). Ret in situ hybridization combined with IB4 immunostaining was performed as previously described (Abdel Samad et al., 2010).

Cell counting. To quantify neurons expressing different molecular markers, L4 and L5 (or T12 when mentioned) DRGs were dissected from 3 different mice, and these DRGs were sectioned into eight adjacent sets with $12 \mu \mathrm{m}$ in thickness. Each set was used for in situ hybridization with a specific probe or for immunostaining with a specific antibody. For each molecular marker, at least three DRGs from different mice were included. Only cells showing clear nuclei were counted. Average and SEM were calculated, and the difference between wild-type and mutant mice was subjected to a Student's $t$ test, with $p<0.05$ considered significant.

Electroporation on spinal cord explants. Full-length mouse Runx1 and Tlx3 cDNAs were subcloned into the replication-competent retroviral vector RCASBP (Morgan and Fekete, 1996), with resulting plasmids referred to as RCASBP-Tlx3 and RCASBP-Runx1 and used for electroporation. The parental empty vector RCASBP was used for control. E12.5 mouse embryonic spinal cords were dissected, and cut into 4-mm-long pieces along the rostrocaudal axis. The dorsal midline was cut to make flat open-book explants as shown below in Figure 6. The explants were placed onto the filter membrane (Millipore catalog \#AABP02500). Plasmid $(1 \mu l)$ was added onto the surface of each spinal explant, and the explants were then electroporated with BTX \#ECM 830 electroporator. Electroporation conditions were as follows: $15 \mathrm{~V}, 50 \mathrm{~ms}, 5$ pluses. For single plasmid electroporation, $1 \mu \mathrm{lof}(2 \mu \mathrm{g} / \mu \mathrm{l})$ of the plasmid was used. For Runx 1 plus Tlx 3 electroporation, $1 \mu \mathrm{g} / \mu \mathrm{l}$ of each plasmid was used. After electroporation, the explants were cultured on the floating filter membranes, using the neural basal medium (Invitrogen 21103049) supplemented with the nerve growth factor NGF (Invitrogen 13257-019) at $25 \mathrm{ng} / \mathrm{ml}, 1 \times$ Glutamax (Invitrogen 35050-061), and 1× B27 (Invitrogen 17504). After $3 \mathrm{~d}$ of culture, the explants were fixed with $4 \%$ PFAPBS and then processed for in situ hybridization.

\section{Results}

\section{Broad Tlx3 expression in TrkA lineage DRG neurons}

Tlx3 is expressed broadly in developing sensory neurons in DRGs at embryonic stages (Shirasawa et al., 2000; Qian et al., 2002), and its expression was also detected at adult stages (Fig. $1 \mathrm{~A}$ ). In lumbar DRGs at P30, Tlx3 was expressed in a majority of small and medium diameter neurons (Fig. $1 A$, arrows), but was excluded from a subset of large and small diameter neurons (Fig. 1A, arrowheads). The TrkA lineage neurons involved with pain, itch, and/or temperature sensations are divided into two subpopulations, the peptidergic neurons marked by persistent expression of TrkA and the neuropeptide CGRP, and nonpeptidergic neurons marked by the expression of Ret and partly by the binding of the isolectin IB4, although a small subset of Ret $^{+}$neurons is also peptidergic (Snider and McMahon, 1998; Bachy et al., 2011; Liu and $\mathrm{Ma}, 2011)$. In P30 lumbar DRGs, Tlx3 was detected in $78 \%$ (319/408) of TrkA ${ }^{+}$neurons, 76\% (170/225) of CGRP ${ }^{+}$neurons, and in $92 \%(532 / 577)$ of $\mathrm{IB}^{+}{ }^{+}$neurons, albeit at variable levels (Fig. $1 B-D$ ). Nearly all neurons that persistently expressed Runx1 also coexpressed Tlx3 (99\%, 612/618) (Fig. 1E), and Runxl was expressed in a subset of $\mathrm{Tlx}^{+}$neurons (Fig. $1 E$ ). Thus, persistent Tlx3 expression is broadly associated with both peptidergic and nonpeptidergic neurons within the TrkA lineage neurons. 

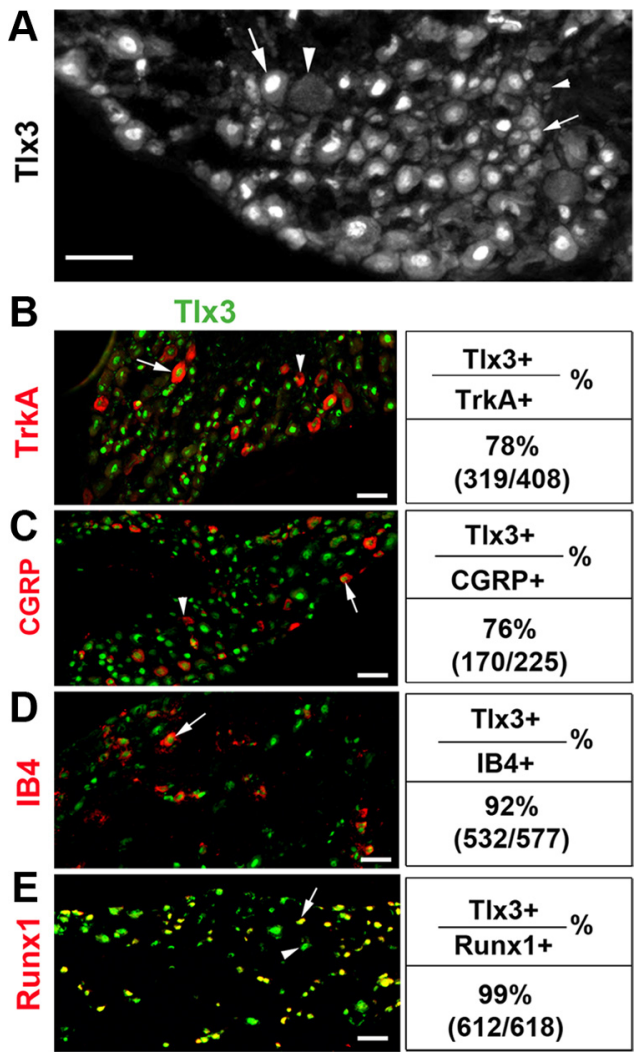

Figure 1. Broad TIx3 expression in small and medium diameter DRG neurons. $A$, Tlx3 immunostaining on a lumbar DRG section of a P30 wild-type mouse. Note detectable TIX3 expression in small and medium diameter neurons (small and large arrows, respectively), but not in some large and small neurons (large and small arrowheads, respectively). $\boldsymbol{B}-\boldsymbol{E}$, Double immunostaining of Tlx3 (green) with indicated markers (red). Arrows indicate double-positive cells. Arrowheads in $\boldsymbol{B}$ and $\boldsymbol{C}$ indicate neurons expressing TrkA or CGRP, but not TIx3, and the arrowhead in $\boldsymbol{E}$ indicates cells expressing Tlx3 but not Runx1. Scale bars, $50 \mu \mathrm{m}$.

We have reported previously that in the dorsal spinal cord, Tlx3 and its related protein Tlx1 determine the excitatory over the inhibitory neuronal cell fate, by activating VGLUT2, the vesicular transporter that packages the glutamate into excitatory vesicles, and suppressing GABAergic neuron markers (Cheng et al., 2004). Mechanistically, Tlx3 acts to suppress the activity of the homeobox protein Lbx1; in the genetic background lacking $L b x 1$, Tlx3 would be no longer required for VGLUT2 expression (Cheng et al., 2005). DRG neurons are glutamatergic (Yoshimura and Jessell, 1990; Brumovsky et al., 2007; Lagerström et al., 2010; Liu et al., 2010). Consistent with a lack of Lbx1 expression in DRG neurons (Gross et al., 2002; Müller et al., 2002), Tlx3 and Tlx 1 are not involved in controlling glutamatergic differentiation in DRG neurons, as indicated by normal VGLUT2 expression and no derepression of GABAergic neuron markers in mice lacking both Tlx3 and Tlx1 (data not shown).

\section{Generation of $T l x 3$ conditional knock-out mice}

Tlx3 conventional null mice die at birth (Shirasawa et al., 2000), which precludes their usage for a detailed analysis of Tlx3 functions in controlling sensory neuron development and maturation. To overcome this, we have generated mice carrying a conditional null allele of $T l \times 3$, referred to as $T l \times 3^{F}$, in which the second exon encoding part of the homeobox domain was flanked with two loxP sites and can thereby be removed by the Cre DNA recombinase (Fig. $2 A-E$ ). We next crossed $T l \times 3^{F}$ mice with Nav1.8-Cre mice, with the resulting conditional null mice re- ferred to as $T l \times 3^{F / F} ; N_{a v 1.8^{C r e /+}}$ (Fig. $2 F, G$ ). Nav1.8-Cre was expressed selectively in $81 \%$ of total DRG neurons (Liu et al., 2010), including $\mathrm{IB}^{+}{ }^{+}$and $\mathrm{CGRP}^{+}$subsets of TrkA lineage neurons (Agarwal et al., 2004). Consistently, Tlx3 expression in DRGs was markedly reduced in $\mathrm{Tl} \times 3^{\mathrm{F} / \mathrm{F}} ; \mathrm{Nav} 1.8^{\mathrm{Cre} /+}$ mice, but not completely eliminated (Fig. 2G). The Tlx $3^{F / F} ; \mathrm{Nav1.8} 8^{\mathrm{Cre} /+}$ mice survived to adulthood, allowing us to examine the roles of Tlx3 in controlling sensory neuron development and maturation, as described below.

Impaired segregation of TrkA ${ }^{+}$versus Ret $^{+}$sensory neurons A key event in TrkA lineage neuron development is perinatal/ postnatal segregation of these neurons into 1) $\mathrm{CGRP}^{+}$peptidergic neurons that retain TrkA expression versus 2) $\mathrm{IB}^{+}{ }^{+}$neurons that switch off TrkA and activate Ret (Bennett et al., 1996; Molliver et al., 1997; Chen et al., 2006; Luo et al., 2007). We found that in P30 lumbar DRGs of Tlx $3^{F / F} ; \mathrm{Nav1.8}{ }^{\mathrm{Cre} /+}$ conditional knockout mice, the levels of Ret expression in $\mathrm{IB}^{+}{ }^{+}$neurons were reduced, but not fully lost (Fig. 3A, data not shown), with IB4 ${ }^{+}$ neurons expressing high level Ret reduced from 69\% (272/397) in control littermates $\left(T l \times 3^{F / F}\right.$ or $T l \times 3^{F /+}$ mice that did not carry Nav1.8-Cre) to $18 \%(64 / 365)$ in $T l x 3^{F / F} ; N a v 1.8^{C r e /+}$ mice. Meanwhile, TrkA expression failed to be extinguished in IB $4^{+}$neurons (Fig. $3 B$ ), with IB4 ${ }^{+}$cells expressing TrkA increased from $13 \%$ (56/435) in wild-type mice to $92 \%(532 / 577)$ in $T l \times 3^{F / F}$; Nav1.8 $8^{\mathrm{re} /+}$ mice. Moreover, for those double-positive cells, TrkA expression levels in IB4 ${ }^{+}$neurons were low in wild-type mice, but medium or high in $T l \times 3^{F / F} ; N a v 1.8^{C r e /+}$ mice (Fig. $3 B$, arrows). In contrast to the dramatic expansion of TrkA expression in $\mathrm{IB}^{+}{ }^{+}$neurons, CGRP expression was, however, only modestly expanded (Fig. 3C), with percentages of $\mathrm{IB} 4^{+}$neurons expressing CGRP increased from 7.7\% (49/637) in wild-type mice to $22 \%(118 / 506)$ in $T l \times 3^{F / F} ; N a v 1.8^{C r e /+}$ mice. Thus, Tlx3 is required to elevate Ret expression and to switch off TrkA, even though most of these neurons $(100-22=78 \%)$ retained the nonpeptidergic identity.

This change in molecular identities in IB $4^{+}$neurons could be further visualized in the dorsal spinal cord. In wild-type control mice, $\mathrm{CGRP}^{+}$and $\mathrm{IB}^{+}{ }^{+}$sensory afferents project to distinct laminae, with 1) $\mathrm{CGRP}^{+}$fibers mainly in the lamina I and the outer layer of lamina II (IIo), and 2) $\mathrm{IB}^{+}$fibers in the inner layer of lamina II (IIi) (Fig. 3D) (Snider and McMahon, 1998). We found that lamina-specific innervations by $\mathrm{CGRP}^{+}$and $\mathrm{IB}^{+}$fibers were largely unchanged in $\mathrm{Tl} \times 3^{\mathrm{F} / \mathrm{F}} ; \mathrm{Nav} 1.8^{\mathrm{Cre} /+}$ mice (Fig. $3 D$ ). TrkA immunostaining, which labeled $\mathrm{CGRP}^{+}$fibers in laminae I and IIo in control mice (Fig. $3 E$ ), was expanded ventrally to colabel IB $4^{+}$fibers in lamina IIi in $T l x 3^{\mathrm{F} / \mathrm{F}} ; \mathrm{Nav1.8^{ \textrm {Cre } / + }}$ mice (Fig. $3 E$ ), thereby confirming the failed extinguishment of TrkA in IB $4{ }^{+}$neurons. The vesicular glutamate transporter VGLUT1 was enriched in mechanoreceptors that innervate in laminae III-V, ventral to $\mathrm{IB}^{+}{ }^{+}$fibers in control mice (Fig. $3 F$ ), and the same innervation pattern was observed in $\mathrm{Tl} x 3^{\mathrm{F} / \mathrm{F}} ; \mathrm{Nav1.8^{ \textrm {Cre } / + }}$ mice (Fig. $3 F$ ), further suggesting that primary afferent innervations in the dorsal spinal cord is largely unchanged in $T l \times 3^{F / F} ; \mathrm{Nav} 1.8^{\mathrm{Cre} /+}$ mice.

Loss of Runx1-dependent ion channels and sensory receptors in $T l \times 3^{F / F} ; N a v 1.8^{C r e /+}$ mice

The impaired segregation of $\operatorname{TrkA}^{+}$versus Ret $^{+}$neurons in $T l \times 3^{F / F} ; \mathrm{Nav1.8} 8^{\mathrm{Cre}++}$ mice is reminiscent of the mutant phenotype observed in Runxl conditional knock-out mice (Chen et al., 2006; Yoshikawa et al., 2007). Runx1 is additionally required for the expression of dozens of sensory channels and receptors (Chen 

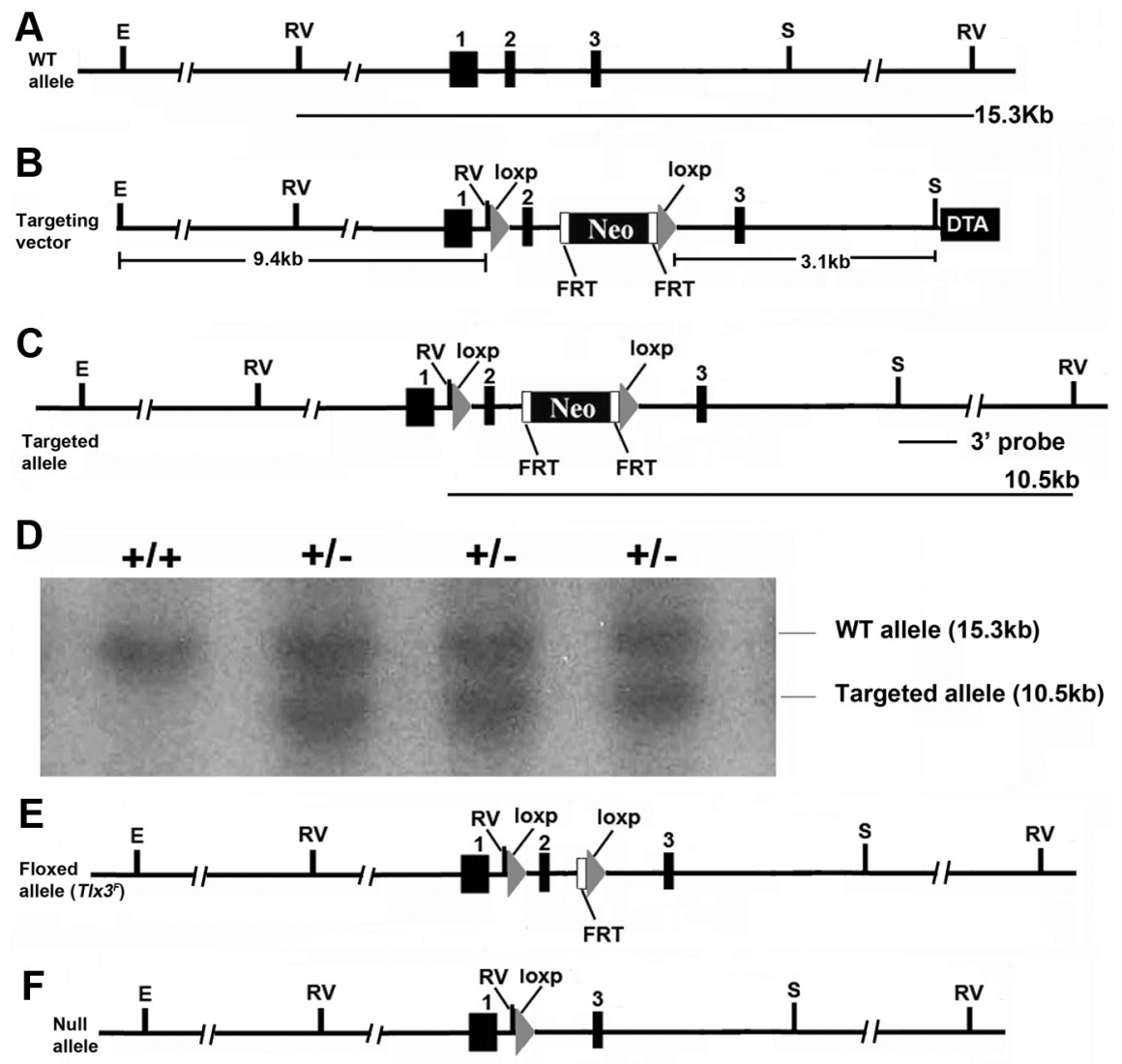

G
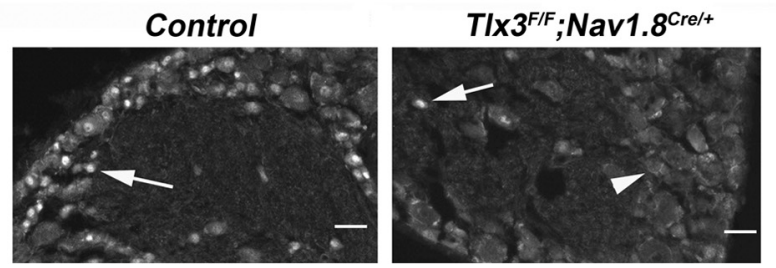

Figure 2. Generation of $T / x 3$ conditional null mice. $\boldsymbol{A}$, The wild-type $T / \times 3$ genomic allele, with solid boxes indicating coding exons (1, 2, and 3). E, EcoR1; RV, EcoRV; S, Sal1. B , The targeting vector, with $9.4 \mathrm{~kb}$ long and $3.1 \mathrm{~kb}$ short recombination arms. The first LoxP site (left triangle, the recognition site for the Cre recombinase) and an exogenous EcoRV (RV) site were introduced into the first intron (between exons 1 and 2). Neo represents the Neo expression cassette for the G418 drug-resistant selection (see Materials and Methods), flanked with two FRT sequences (recognition sites for the Flipase recombinase) and the second LoxP site, as indicated in the schematics. DTA, The expression cassette that drives the expression of DTA for negative section. $\boldsymbol{C}$, The targeted $T / x 3$ allele after successful homologous recombination. $D$, Genomic Southern hybridization revealing three of four selected embryonic stem cell clones undergoing successful targeting. Using the $3^{\prime}$ probe indicated in $\boldsymbol{C}$, EcoRV digestion generated a $15.3 \mathrm{~kb}$ genomic fragment for the wild-type allele (see $\boldsymbol{A}$ ), and a $10.5 \mathrm{~kb}$ fragment for the targeted allele (see $\boldsymbol{C}$ ). $\boldsymbol{E}$, The floxed $T / \times 3$ allele, after removal of the neo cassette by Flipase-mediated DNA recombination (see Materials and Methods). $\boldsymbol{F}$, The T/x3 conditional null allele upon removal of the second coding exon through Cre-mediated DNA recombination. G, Immunostaining showing a loss of TIX3 expression in most P30 lumbar DRGs in T/X3 conditional knock-out mice, or T/X ${ }^{\mathrm{F} / \mathrm{F}}$;Nav1.8 $8^{\mathrm{Cre} /+}$ mice (arrowhead), in comparison with that in control littermates (left, arrow). Only few neurons in $T / x 3^{F / F} ; N a v 1.8^{C r e /+}$ mice retained Tlx3 expression (right, arrow). Scale bars, $50 \mu \mathrm{m}$.

et al., 2006; Abdel Samad et al., 2010). To determine whether Tlx3 is involved in regulating sensory channels/receptors, we performed a series of in situ hybridization on sections through lumbar or thoracic DRGs from P30 Tlx $3^{F / F} ; \mathrm{Nav1.8}$ Cre/+ and control mice. Remarkably, expression of virtually every Runx1dependent gene examined thus far was either eliminated or markedly reduced in $T l \times 3^{F / F} ; \mathrm{Nav} 1.8^{\mathrm{Cre} /+}$ mice (Fig. 4). As described below, these genes encode sensory channels and receptors involved with pain, itch and/or temperature sensation.

Mrgprd, a mas-related G-protein coupled receptor (GPCR), is a marker for a large group of polymodal nociceptors that represent $30 \%$ of total DRG neurons, innervate exclusively the skin epidermis, and are involved with mechanical pain sensation (Zylka et al., 2005; Imamachi et al., 2009; Rau et al., 2009). In P30 Tlx $3^{F / F} ;$ Nav1.8 $8^{\text {Cre/+ }}$ mice, Mrgprd expression was greatly reduced, but not completely eliminated (Fig. 4A). As described below, a complete loss of Mrgprd expression was observed in Tlx 3 complete null mice. Mrgprd ${ }^{+}$neurons express a set of other Runx1-dependent genes, including those encoding the Mrgprd-related Mrgprb5 and the sodium channel Nav1.9, respectively (Abdel Samad et al., 2010). Expression of Mrgprb5, whose mRNA was somehow enriched in the nuclei, was eliminated (Fig. 4A), and Nav1.9 was largely eliminated in DRGs of $T l \times 3^{F / F} ; \mathrm{Nav} 1.8^{\mathrm{Cre} /+}$ mice (Fig. 4A). The ATP-gated channel $\mathrm{P} 2 \mathrm{X} 3$ is expressed in both IB4 ${ }^{+}$and IB4 neurons, and its expression in $\mathrm{IB}^{+}$neurons is selectively dependent on Runxl (Abdel Samad et al., 2010). We found that P2X3 expression in lumbar DRG neurons was also reduced in $T l \times 3^{F / F} ; N a v 1.8^{C r e /+}$ mice, with $\mathrm{IB}^{+}{ }^{+}$neurons coexpressing $\mathrm{P} 2 \mathrm{X} 3$ reduced from $50 \%$ (346/689) in control mice to $17 \%$ $(96 / 566)$ in $T l \times 3^{F / F} ; N a v 1.8^{C r e /+}$ mice (data not shown). Thus, Tlx 3 is required to establish a set of Runx1-dependent molecular identities in Mrgprd ${ }^{+}$polymodal nociceptors, including Ret, Mrgprd, Mrgprb5, P2X3, and Nav1.9.

Another Mrgpr class GPCR, Mrgpra3, mediates histamine-independent itch (Liu et al., 2009). Its expression in lumbar DRGs was eliminated in $T l \times 3^{F / F}$; Nav1. $8^{\mathrm{Cre} /+}$ mice (Fig. 4 B). Expression of Mrgprb4, which marks a group of sensory neurons that innervate the hairy skin and are hypothesized to mediate pleasant touch (Liu et al., 2007), was also eliminated in P30 Tl $x 3^{F / F} ; \mathrm{Nav1.8}$ Cre/+ mice (Fig. 4C). Thus, Tlx3 is necessary for the expression of most members of Mrgpr class GPCRs, as Runx1 does (Chen et al., 2006; Liu et al., 2008).

The transient receptor potential (TRP) channels are involved with pain, itch, and thermal sensations (Basbaum et al., 2009; Patel and Dong, 2011), whose expression is partially dependent on Runxl (Chen et al., 2006). TRPA1 is involved in sensing chemical pain (Basbaum et al., 2009) and histamine-independent itch (Wilson et al., 2011). In wild-type mice, high level TRPA1 expression (TRPA1 ${ }^{\text {high }}$ ) was enriched in cervical and thoracic DRGs (data not shown), whereas a lower level of TRPA1 expression was detected in lumbar DRGs (Fig. 4D) (Abdel Samad et al., 2010). We found that no TRPA1 expression in lumbar DRGs was detected in P30 Tl $x 3^{F / F} ;$ Nav1.8 $8^{\text {Cre/+ }}$ mice (Fig. $4 D$ ), as the situation seen in Runx1 mutant mice (Abdel Samad et al., 2010). TRPA1 expression in thoracic DRGs was also greatly reduced, but not completely eliminated (data not shown). Neurons expressing TRPM8, a cold-sensing receptor (Basbaum et al., 2009), was re- 


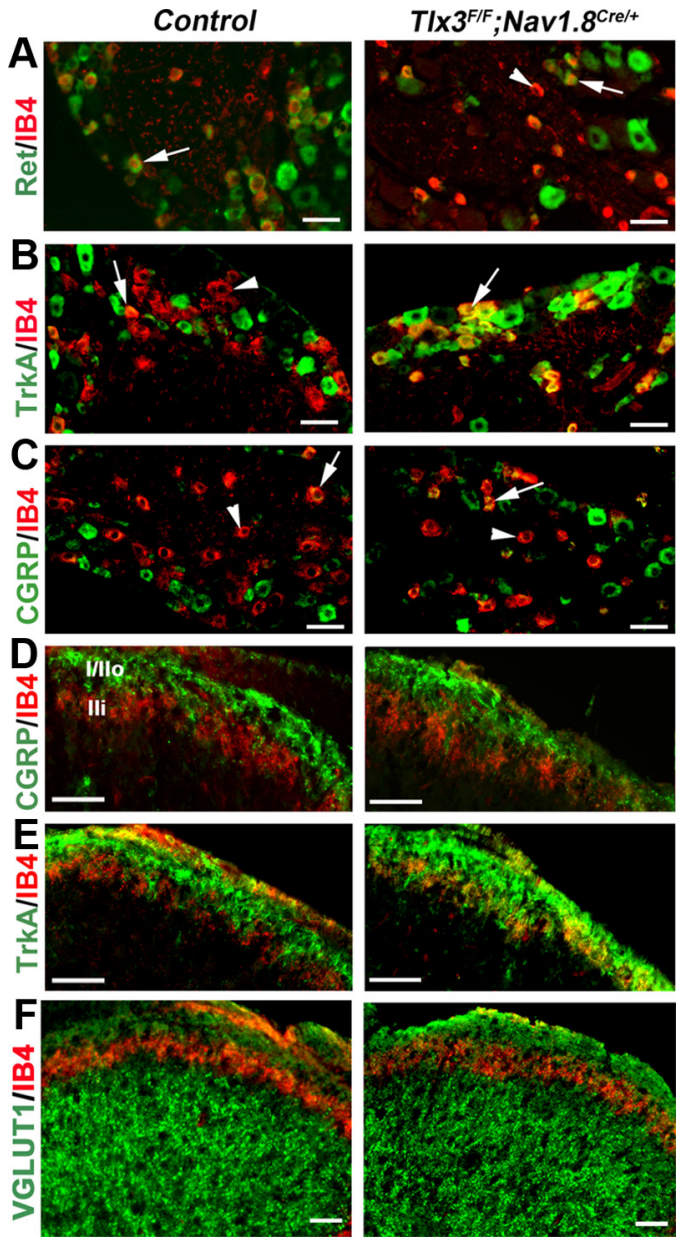

Figure 3. Impaired segregation of Ret ${ }^{+}$versus TrkA ${ }^{+}$neurons in $\mathrm{Tl} \times 3^{\mathrm{F} / \mathrm{F}} ; \mathrm{Nav} 1.8^{\mathrm{Cr} /+}$ mice. $\boldsymbol{A}-\boldsymbol{C}$, A combination of IB4 binding (red) with Ret mRNA ( $\boldsymbol{A}$, green) detected by in situ hybridization, or the TrkA protein ( $\boldsymbol{B}$, green), or the (GRP peptide ( $\boldsymbol{C}$, green) detected by immunostaining on P30 lumbar DRG sections. Arrows in $\boldsymbol{A}$ indicate high-level Ret expression in both panels, and the arrowhead indicates reduced Ret expression in $\mathrm{IB} 4^{+}$neurons in $\mathrm{Tl} \times 3^{\mathrm{F} / \mathrm{F}} ; \mathrm{Nav1.8} 8^{\mathrm{Cre} /+}$ mice. In $\boldsymbol{B}$, the arrow and arrowhead in the left panel indicate low and nondetectable TrkA expression in IB4 ${ }^{+}$neurons in control mice, and the arrow in the right panel indicates elevated TrkA expression in $\mathrm{T} / \mathrm{x}^{\mathrm{F} / \mathrm{F}} ; \mathrm{Nav1} 18^{\mathrm{Cr} /+}$ mice. In C, arrows and arrowheads indicate neurons with detectable and nondetectable CGRP expression, respectively. $\boldsymbol{D}-\boldsymbol{F}$, A combination of IB4 binding (red) with immunostaining against CGRP, TrkA, or VGLUT1 (green) on transverse sections through P30 spinal cords. I/llo, Lamina I and the outer layer of lamina II; Ili, inner layer of lamina II. Scale bars, $50 \mu \mathrm{m}$ in length.

duced by $45 \%$ (Fig. $4 D$ ), from $74 \pm 3.3$ per set of DRG sections in control mice to $41 \pm 5.4$ in $T l x 3^{F / F} ; \mathrm{Nav1.8} 8^{\mathrm{Cre} /+}$ mice at $\mathrm{P} 30(p<$ 0.005). As described below, the reduction of TRPM8 expression was more complete in Tlx3 complete null mice.

TRPV1 is a polymodal receptor that senses warm, heat, itch, acid, and other chemicals (Woolf and Ma, 2007; Shim and Oh, 2008; Basbaum et al., 2009). Approximately 10\% of TRPV1 ${ }^{+}$ neurons express extremely high levels of TRPV1 (TRPV 1 high) (Chen et al., 2006; Abdel Samad et al., 2010), and these neurons selectively innervate the skin epidermis and sense warm and mild heat (Kiasalari et al., 2010). Runxl is required to establish TRPV $1{ }^{\text {high }}$ expression, but dispensable for low levels of TRPV1 expression (Chen et al., 2006). Maintenance of a portion of TRPV $1{ }^{\text {high }}$ expression is, however, independent of Runx1, as indicated by a partial loss of TRPV $1^{\text {high }}$ neurons in late Runx1 conditional knock-out mice using Nav1.8-Cre that removed Runx1 around E17 (Abdel Samad et al., 2010). In $T l \times 3^{F / F}$;
Nav1. ${ }^{\mathrm{Cre} /+}$ conditional knock-out mice using the same Nav1.8Cre, we still observed TRPV 1 high neurons (Fig. $4 D$, arrow), although it remains unclear whether the number was reduced. As described below, TRPV $1{ }^{\text {high }}$ neurons were, however, nearly completely eliminated in Tlx3 complete null mice. Low or medium levels of TRPV1 expression were unaffected in either $T l \times 3^{F / F}$; Nav1. $8^{\mathrm{Cre} /+}$ mice at P30 (Fig. $4 \mathrm{D}$, arrowhead) or Tl 3 complete null mice at P0 (see below), as the case seen in early and late Runx1 knock-out mice (Chen et al., 2006; Abdel Samad et al., 2010).

In Figure 3, we have shown that Tlx3 does not have a positive role in controlling the expression of two Runxl-independent (or actually Runx1-suppressed) peptidergic neuron markers, TrkA and CGRP. Expression of other Runxl-independent genes was also unaffected (if not increased) in $\mathrm{Tl} \times 3^{\mathrm{F} / \mathrm{F}} ; \mathrm{Nav} 1.8^{\mathrm{Cre} /+}$ mice, including DRASIC encoding an acid sensing channel and Tac1 (the preprotachykinin 1 gene) encoding the neuropeptide SP (Fig. $4 E$ ). All together, $T l x 3$ is required selectively to establish Runx1dependent molecular phenotypes, despite of its broad expression in TrkA lineage neurons.

\section{Tlx3 and Runx1 are independently regulated}

To gain insight into how Tlx3 and Runx1 establish sensory phenotypes, we next analyzed and compared Tlx3 and Runx 1 mutant mice at E16.5 or in newly born mice, when the expression of a few Tlx3- and Runx1-dependent receptors has just been established in wild-type mice (Chen et al., 2006). For this analysis, the Tlx3 complete null mice (Shirasawa et al., 2000) were used such that the Tlx3 activity was eliminated from the very beginning. Meanwhile, mice with a conditional knock-out of Runxl in sensory precursor using Wnt1-Cre (Runx $\left.1^{F / F} ; W n t 1^{C r e /+}\right)$ were used for a comparison. We had previously reported that expression of Mrgprd and TRPM8 is eliminated in $R u n x 1^{F / F} ; W n t 1^{C r e /+}$ mice at E16.5 (Chen et al., 2006). Here we found that Mrgprd expression was also eliminated in $T l \times 3$ complete null mice at E16.5 (Fig. 5A). Expression of TRPM8 was, however, still detected at E16.5, but greatly reduced at $\mathrm{P} 0$ in Tlx3 null DRGs, suggesting that Tlx3 is required to maintain, but not to initiate, TRPM8 expression. It should be noted that neurons with weak expression of TRPM8 were still observed in $T l \times 3$ null DRGs (Fig. $5 A$, arrow), indicating that at least a portion of TRPM8-expressing neurons survived, which in turn suggests a requirement of Tlx3 for elevated TRPM8 expression. For TRPV1, TRPV 1 high expression was eliminated in Tlx3 null mice (Fig. 5A, arrows), whereas low and medium levels of TRPV1 expression were unaffected (Fig. $5 A$, arrowheads), as the situation seen in early Runxl knock-out mice (Chen et al., 2006; data not shown).

Importantly, expression of Runx1 itself was grossly unaffected in Tlx3 null mice at E16.5 (Fig. 5B) or at P0 (data not shown). Conversely, Tlx3 expression was unchanged in Runx1 $1^{F / F}$;Wnt1Cre mice at P0 (Fig. 5C). Thus, during the period when both Tlx3 and Runx 1 are required to establish Mrgprd and TRPV $1{ }^{\text {high }}$ expression, expression of Tlx3 and Runxl appears to be independently regulated, suggesting that genetically, these two transcription factors might act in combination to control the expression of sensory channels and receptors, although their action modes can be different (see below, Discussion).

\section{Overexpression of Tlx3 and Runx1 was able to induce sensory channels/receptors}

We next asked whether overexpression of Tlx3 and Runx1, singly or in combination, was able to activate sensory channels 

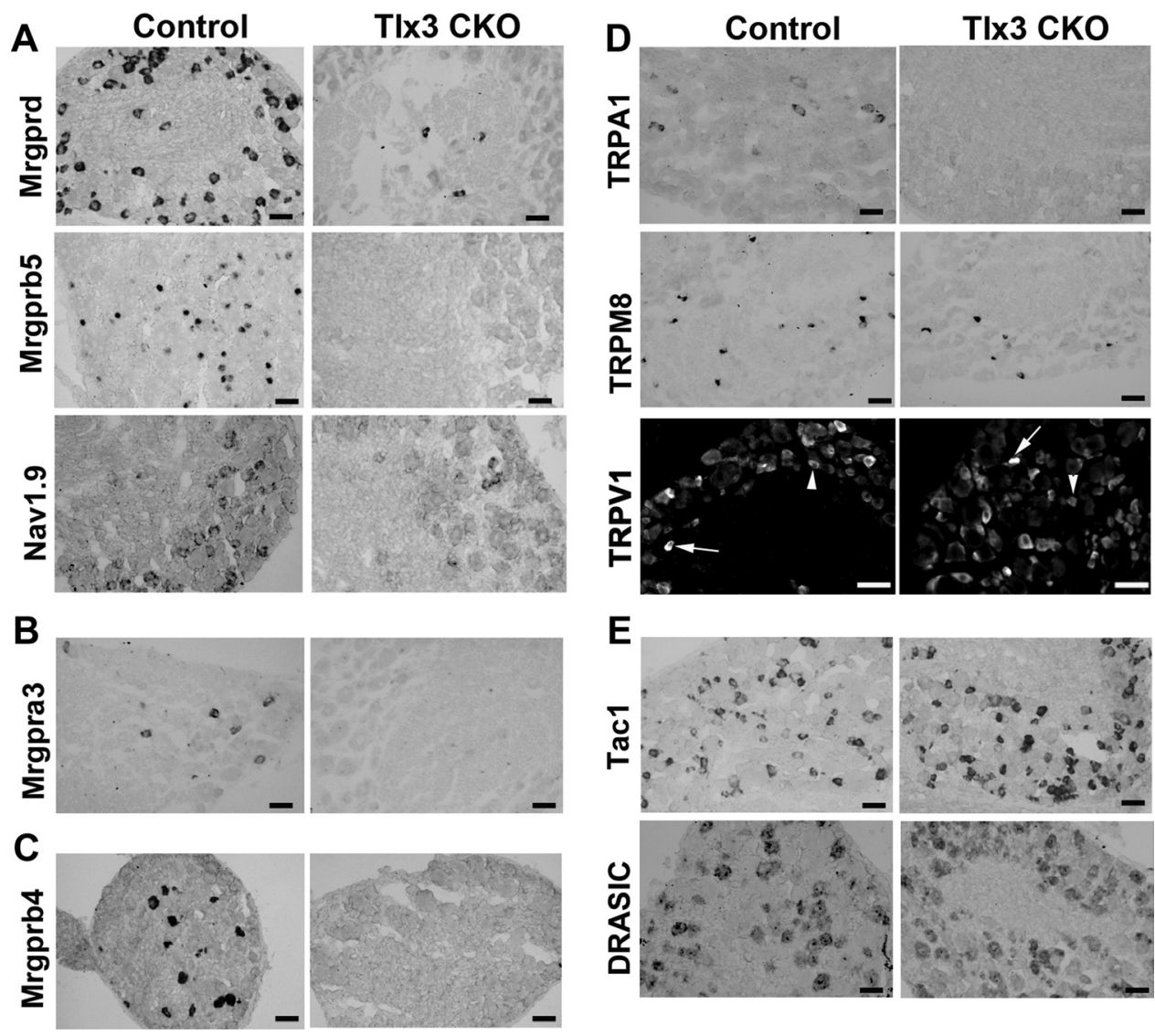

Figure 4. Loss of expression of sensory receptors and ion channels in $T / x 3^{\mathrm{F} / F} ; \mathrm{Nav} 1.8^{\mathrm{Cr} e /+}$ mice compared with littermate control. $\boldsymbol{A}-\boldsymbol{E}$, In situ hybridization with indicated probes on sections through lumbar DRGs $(\boldsymbol{A}, \boldsymbol{B}, \boldsymbol{D}, \boldsymbol{E})$ or thoracic DRGs $(\boldsymbol{C})$, with the exception of TRPV1 in $\boldsymbol{D}$, which was detected by immunostaining. Arrow in $\boldsymbol{D}$ indicates extremely high-level TRPV1 expression, and arrowheads indicate low or medium levels of expression. Scale bars, $50 \mu \mathrm{m}$ in length.

and receptors in heterologous systems. To do this, we performed gain-of-function analyses, using electroporation onto the ventricular zone of the "open-book" explants of the E12.5 mouse spinal cord (Fig. 6A). After electroporation, the explants were cultured for $3 \mathrm{~d}$ on floating membranes with neural basal medium containing the nerve growth factor. Electroporation of the Tlx 3 or Runx1 expression plasmid led to a robust expression of exogenous Tlx3 (Fig. 6B) or Runx1 (data not shown) on the surface of the explants. We then found that electroporation of the control vector RCASBP was unable to induce any of molecules examined (Fig. $6 \mathrm{C}$ ). Electroporation of the Tlx3 expression vector alone was able to induce MrgprA3, but not Mrgprd, TRPM8, P2X3, Ret or Nav1.9. Electroporation of the Runx1 expression vector was able to induce MrgprA3, Mrgprd, TRPM8, P2X3 and Ret, albeit at variable levels, but unable to induce Nav1.9 (Fig. 6C). Electroporation of Tlx3 plus Runx1 resulted in robust induction for all these six molecules. Thus, when expressed at exceedingly high levels following electroporation, exogenous Runx1 is able to induce a subset of sensory channels and receptors, but a combination of Runx 1 and Tlx3 is generally more efficient in doing so. However, it needs to be pointed out that when expressed at the physiological level or in the context of developing DRG neurons, both Runx 1 and Tlx 3 are needed to establish most sensory channels and receptors, as indicated by the loss or reduced expression of these molecules in Runx1 or Tlx3 deficient mice.

Furthermore, in the absence of the nerve growth factor in the cultured medium, Tlx3 plus Runx1 was unable to induce any of these ion channels and receptors (data not shown), consistent with the reported requirement of the TrkA signaling for the establishment of most Runx1-dependent genes (Luo et al., 2007).

\section{Discussion}

Tlx 3 controls proper segregation of Ret ${ }^{+}$versus $\operatorname{TrkA}^{+}$ subpopulations of somatic sensory neurons

The homeodomain protein Tlx 3 is broadly expressed in somatic sensory neurons, including both Runx1-dependent Ret ${ }^{+}$nonpeptidergic neurons (a majority of them can be labeled by IB4), and Runx 1 -independent peptidergic neurons marked by the expression of TrkA and CGRP (Fig. 1). Both populations are derived from embryonic TrkA-expressing neurons, collectively referred to as TrkA lineage neurons. Despite of the broad expression, the genetic data presented here suggest that Tlx 3 appears to be required selectively for the development of the Runx1dependent Ret $^{+}$subset of TrkA lineage neurons.

First, during segregation of the TrkA lineage neurons into Ret $^{+} ; \mathrm{IB} 4{ }^{+}$versus $\mathrm{TrkA}^{+} ; \mathrm{CGRP}^{+}$subtypes, both Runxl and $T l \times 3$ are required to drive a high level of Ret expression and to switch off TrkA, with a knock-out of either Tlx3 or Runx1 leading to a concurrent reduction of Ret and an expansion of TrkA in $\mathrm{IB}^{+}{ }^{+}$neurons. It should, however, be noted that Tlx 3 is only partially involved in controlling this segregation process. While in Runx1 knock-out mice CGRP is dramatically derepressed in $\mathrm{IB}^{+}{ }^{+}$neurons (Chen et al., 2006; Abdel Samad et al., 2010), only a modest CGRP derepression occurs in Tlx3 mutant mice (Fig. 3). Furthermore, Runx 1 is required for $\mathrm{IB}^{+}{ }^{+}$neurons to innervate lamina IIi in the dorsal spinal cord; in both early (using Wnt1- 
A

A

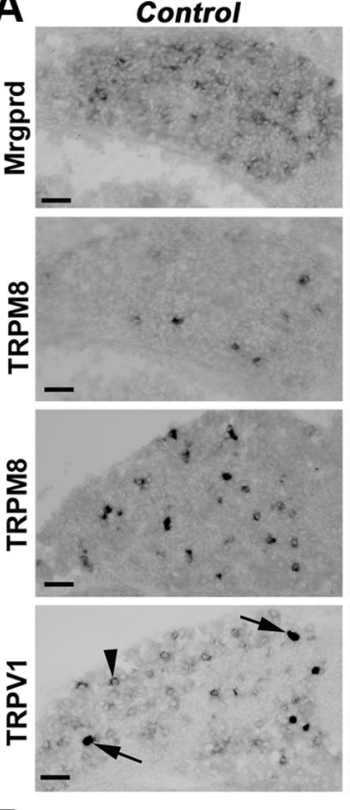

B

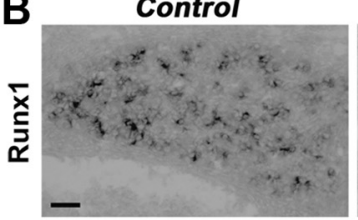

c

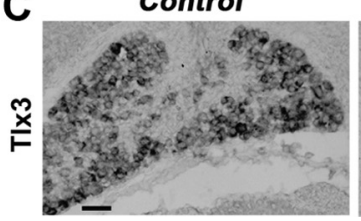

TIX3-/-

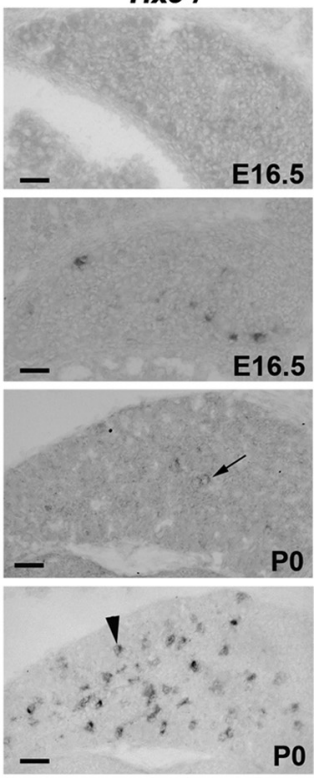

TIX3-/-

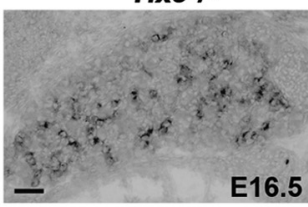

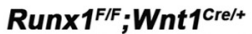

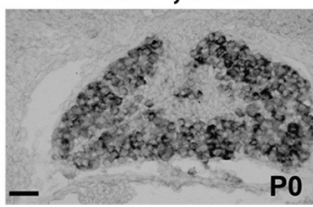

Figure 5. Changes in sensory receptor expression in T/x3 complete null mice at embryonic or neonatal stages and independent regulation of T|x3 versus Runx1. A, $B$, In situ hybridization with indicated probes on sections through E16.5 or P0 lumbar DRGs of wild-type control or T/X3 null mice. For TRPM8 panels, the small arrow indicates neurons with weak TRPM8 expression in T/X3 null mice. For TRPV1 panels, arrows indicate neurons with extremely high levels of TRPV1 expression in the control DRGs, and such neurons are absent in the T/x3 null DRGs. Arrowheads indicate neurons with medium or low levels of TRPV1 expression. C, Unchanged T/x3 expression in lumbar DRGs of P0 control mice versus Runx 1 conditional knock-out mice (Runx $7^{\mathrm{F} / \mathrm{F}} ; \mathrm{Wnt}^{\mathrm{Cre/+}}{ }^{+}$). Scale bars, $50 \mu \mathrm{m}$.

Cre) and late (using Nav1.8-Cre) Runxl knock-out mice, these fibers switch to innervate the more superficial laminae (Chen et al., 2006; Abdel Samad et al., 2010). In contrast, no obvious switch on lamina-specific innervations was observed in Tlx3 conditional knock-out mice (Fig. 3). Thus, Runx1 uses both Tlx3dependent and Tlx3-independent pathways to control molecular and anatomical segregation of two TrkA lineage sensory neuron subtypes, Ret $^{+} ; \mathrm{IB}^{+}{ }^{+}$versus $\operatorname{TrkA}^{+} ; \mathrm{CGRP}^{+}$.

Second, Tlx 3 is required for the expression of virtually all known Runx1-dependent sensory receptors and ion channels that are enriched in Ret $^{+}$neurons, such as Ret, the entire Mrgpr family of GPCRs, P2X3, and Nav1.9. In contrast, expression of a set of Runx1-independent genes that are enriched in TrkA ${ }^{+}$peptidergic neurons, including those encoding TrkA, CGRP, and SP, is either expanded or unchanged in Tlx3 mutants. Notably, Tlx3 and Runx 1 appear to be independently regulated at perinatal and neonatal stages when they first establish the expression of a set of sensory channels and receptors, and overexpression of Runx1

plus Tlx3 is sufficient to induce robust ectopic expression of these molecules. Collectively, these observations suggest that Runx1 acts in combination with Tlx3 to control the molecular identities of the Ret ${ }^{+}$subset of TrkA lineage neurons.

Two other broadly distributed homeobox proteins, Brn3a and Islet1, also play pivotal roles in controlling sensory neuron development (Huang et al., 1999; Ma et al., 2003; Eng et al., 2004; Lei et al., 2006; Sun et al., 2008; Lanier et al., 2009; Dykes et al., 2010, 2011; Zou et al., 2012). Both Brn3a and Islet1 are necessary for the expression of a set of Runx1/Tlx3-dependent sensory channels and receptors, and they act partly by controlling Runx1 expression (Sun et al., 2008; Dykes et al., 2010). However, Brn3a and Runx1 can have opposing activities. During segregation of Ret ${ }^{+}$ versus $\mathrm{TrkA}^{+}$neurons, Brn3a acts to promote TrkA and suppress Ret (Ma et al., 2003; Lei et al., 2006; Zou et al., 2012), exactly opposite to what Runx1 and Tlx3 do: activating Ret and suppressing TrkA (Chen et al., 2006; Yoshikawa et al., 2007). How exactly Brn3a positively and negatively interfaces with Runx1 (and Tlx3) in establishing distinct aspects of sensory neuron identities remains to be investigated.

\section{Distinct control modes used by Runx1 and Tlx 3 in establishing distinct somatic sensory modalities}

One key question in studying sensory neuron development is to understand how distinct sensory modalities are specified. Neurons expressing Tlx3/Runxl-dependent channels and receptors are composed of multiple sensory modalities, including 1) painrelated nociceptors (such as Mrgprd ${ }^{+}$polymodal nociceptors for mechanical pain and TRPA1 ${ }^{+}$nociceptors for sensing noxious chemical and possibly cold pain), 2) thermoceptors (TRPM8 ${ }^{+}$ cold-sensing neurons and TRPV $1^{\text {high }}$ warm/heat-sensing neurons), and 3) pruriceptors (MrgprA3 ${ }^{+}$itch-sensing neurons) (Basbaum et al., 2009; Kiasalari et al., 2010; Patel and Dong, 2011). Interestingly, Runx1 and Tlx3 appear to use distinct action modes in establishing distinct sensory modalities.

First, Runx 1 and Tlx3 operate at different times in controlling the development of Mrgpra3 ${ }^{+}$itch-sensing pruriceptors. Expression of Mrgpra3 was absent in early Runx1 conditional knockout, in which Runx1 was removed in sensory precursors by using Wnt1-Cre mice (Chen et al., 2006). However, when Runx1 was removed at a later stage (around E17) by using the Nav1.8-Cre mice, expression of Mrgpra3 was no longer affected (Abdel Samad et al., 2010). In fact, Runx1 makes a switch from acting as an activator to a repressor in regulating Mrgpra3 expression (in genetic terms); as a result, Mrgpra3 expression can only be sustained in neurons with transient Runxl expression (Liu et al., 2008). In contrast, Mrgpra3 expression is still eliminated in Tlx3 CKO mice using the same Nav1.8-Cre, suggesting that Tlx3 activity operates beyond E17 to control the development of these pruriceptors (Fig. 4). We propose the following temporal control model: Runxl operates before E17 to establish a competent state for subsequent Tlx3-mediated activation of Mrgpra3 at perinatal and neonatal stages. This control mechanism is analogous to the sequential involvement of Runx 1 and Pax 5 in controlling mb-1 expression in the developing B cells of the immune system (Maier et al., 2004). It also suggests that when two transcription factors genetically act in combination, they do not have to form a protein complex, but could also operate through sequential events.

Second, the development of TRPM8 ${ }^{+}$cold-sensing thermoceptors is also subjected to a complex temporal control. Runx1, but not Tlx3, is required to initiate TRPM8 expression at E16.5, and Tlx3 activity is required to maintain elevated TRPM8 expression after E16.5. Surprisingly, while TRPM8 expression levels are 
A

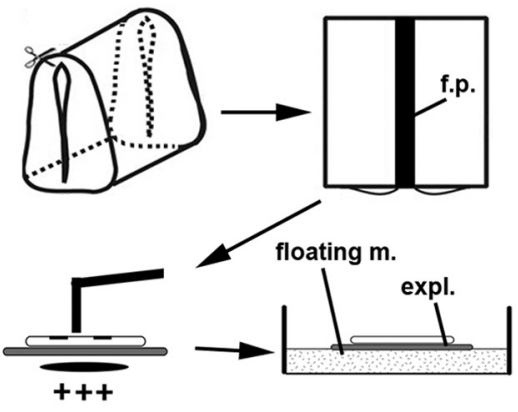

B

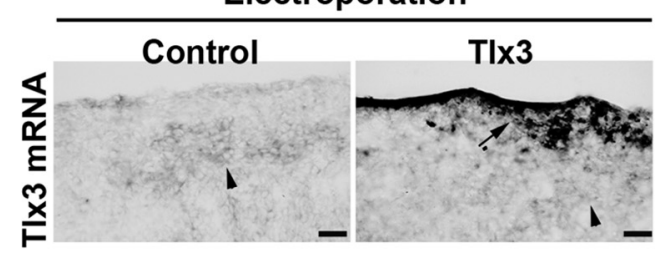

C

Electroporation
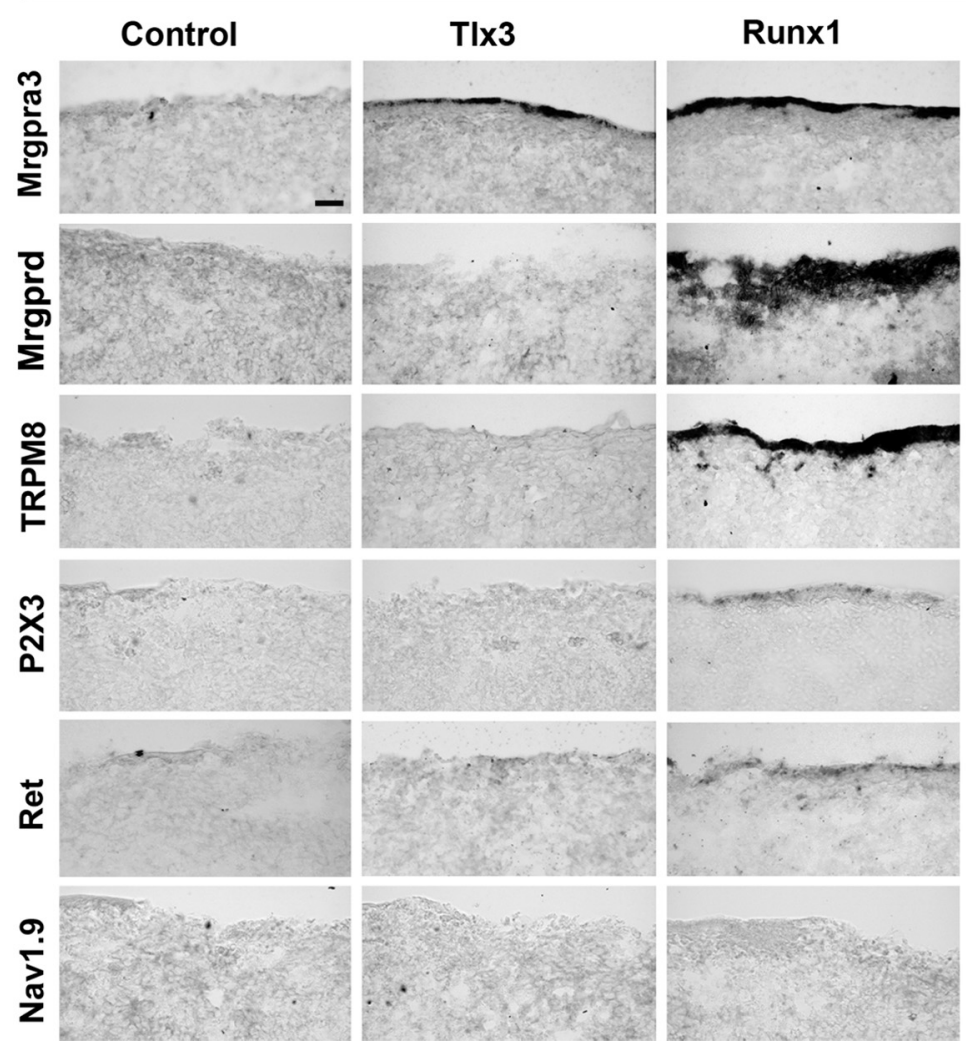

Tlx3 + Runx1
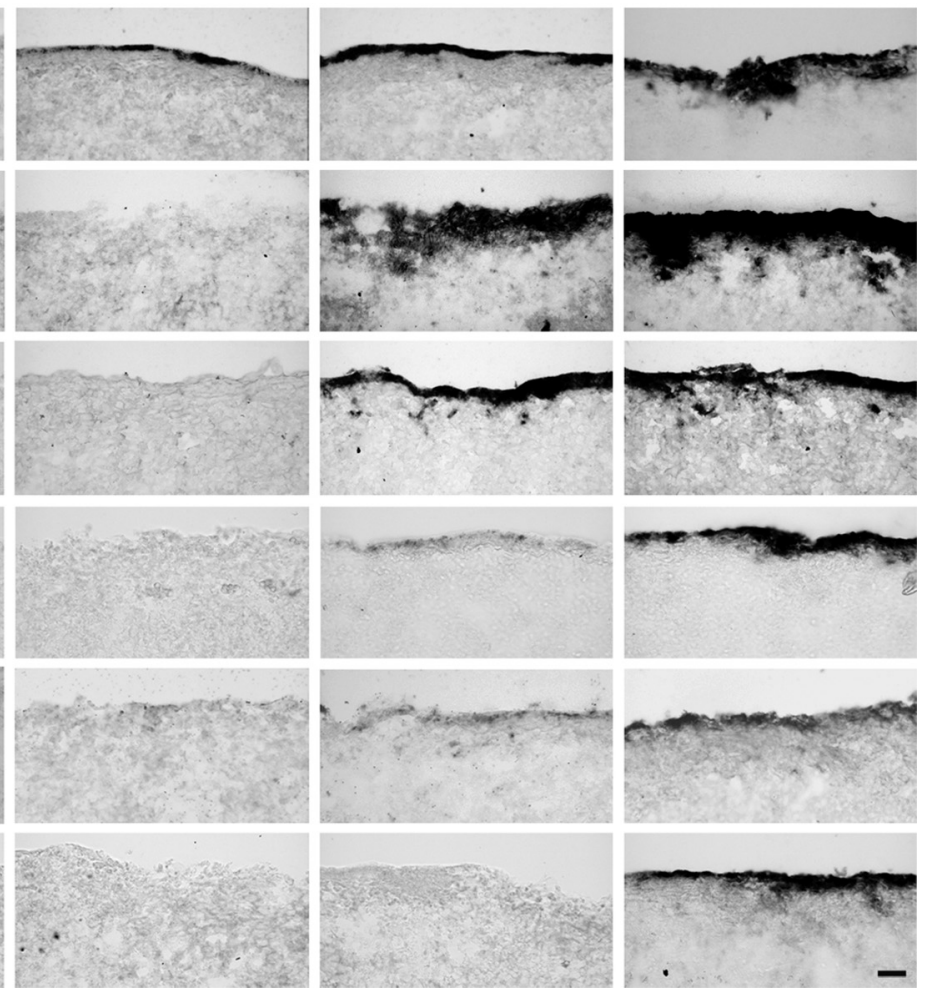

Figure 6. Ectopic induction of sensory channels and receptors by TIx3 and/or Runx1. A, Schematics showing electroporation and culture of embryonic (E12.5) spinal cord explants. f.p., Floor plate; + and -, direction of electric current during electroporation; floating m., filter membrane floating on the surface of the cultured medium; expl., spinal cord explant. $\boldsymbol{B}$, Electroporation of the RCASBP-TIx3 expression plasmid (TIx3 under the line), but not the control RCASBP plasmid (Control), led to robust expression of exogenous Tlx3 mRNA (arrow) detected by in situ hybridization on the surface of the explant (after $3 \mathrm{~d}$ culture). With a short period of color development following in situ hybridization, endogenous Tlx3 mRNA was only weakly detected (arrowhead). C, Mrgpra3, Mrgprd, TRPM8, P2X3, Ret, and Nav1.9 mRNAs were detected by in situ hybridization following electroporation on the explants with the control plasmid (Control), or the plasmid expressing Tlx3 (Tlx3) or Runx1 (Runx1), or mixed plasmids expressing both Tlx3 and Runx1 (Tlx3 + Runx1).

greatly reduced in Tlx3 complete null mice at P0, strong TRPM8 expression is observed in a conditional knock-out of Tlx3 using Nav1.8-Cre (removing Tlx3 around E17), even though the number of neurons is reduced. This finding suggests that persistent presence of Tlx3 per se is not required to maintain TRPM8 expression in a subset of TRPM8 ${ }^{+}$sensory neurons; rather Tlx 3 activity before E17 is required to establish a competent state for other factors to maintain TRPM8 expression at later stages. TRPM8 expression is also absent in Brn3a null mice and partially lost in Islet1 conditional knock-out mice (Sun et al., 2008), and further studies are needed to determine how exactly Runx1, Tlx3, Brn3a, and Islet1 establish and maintain TRPM8 expression.

Third, TRPV $1^{\text {high }}$ neurons have been recently shown to sense warm and mild heat, but not noxious heat (Kiasalari et al., 2010). TRPV $1^{\text {high }}$ neurons are absent in both Tlx 3 complete null mice
(Fig. 5) and early Runxl knock-out mice using Wnt1-Cre (Chen et al., 2006), but a portion of them is still observed in either late Tlx3 (Fig. 4) or late Runx1 (Abdel Samad et al., 2010) conditional knock-outs using the same Nav1.8-Cre. Thus, early Runxl and Tlx3 activity is necessary for proper development of TRPV 1 high neurons, but neither Runx 1 nor $T l x 3$ is required to maintain a portion of these thermoceptors. Islet1 appears to play a more prominent role in controlling TRPV1 expression, as suggested by the apparent loss of both TRPV $1^{\text {high }}$ and TRPV $1^{\text {low }}$ expression in Islet 1 deficient mice (Sun et al., 2008), but it remains unknown how exactly Islet 1 interfaces with Runx 1 and Tlx 3 in controlling TRPV1 $1^{\text {high }}$ expression.

Finally, Runx 1 and Tlx 3 exhibit similar temporal activities in controlling the development of a large group of polymodal nociceptors marked by the coexpression of Mrgprd, Mrgprb5, 
Nav1.9, and P2X3. The development of these neurons is impaired in mice following a conditional knock-out of either Runxl (Abdel Samad et al., 2010) or Tlx3 (Fig. 4) by using the same Nav1.8-Cre mice, suggesting that both Runx1 and Tlx3 operate beyond E17 to establish and/or maintain the expression of this set of genes. Collectively, our studies suggest that Tlx3 and Runx1 use distinct action modes to control the development of distinct somatic sensory modalities within the Ret $^{+}$subset of TrkA lineage neurons. Future studies will be directed to determine how such dynamic Runx 1 and Tlx3 activities are regulated during development.

\section{References}

Abdel Samad O, Liu Y, Yang FC, Kramer I, Arber S, Ma Q (2010) Characterization of two Runx1-dependent nociceptor differentiation programs necessary for inflammatory versus neuropathic pain. Mol Pain 6:45.

Agarwal N, Offermanns S, Kuner R (2004) Conditional gene deletion in primary nociceptive neurons of trigeminal ganglia and dorsal root ganglia. Genesis 38:122-129.

Bachy I, Franck MC, Li L, Abdo H, Pattyn A, Ernfors P (2011) The transcription factor Cux2 marks development of an A-delta sublineage of TrkA sensory neurons. Dev Biol 360:77-86.

Basbaum AI, Bautista DM, Scherrer G, Julius D (2009) Cellular and molecular mechanisms of pain. Cell 139:267-284.

Bennett DL, Averill S, Clary DO, Priestley JV, McMahon SB (1996) Postnatal changes in the expression of the trkA high-affinity NGF receptor in primary sensory neurons. Eur J Neurosci 8:2204-2208.

Brumovsky P, Watanabe M, Hökfelt T (2007) Expression of the vesicular glutamate transporters- 1 and -2 in adult mouse dorsal root ganglia and spinal cord and their regulation by nerve injury. Neuroscience $147: 469-490$

Chen CL, Broom DC, Liu Y, de Nooij JC, Li Z, Cen C, Samad OA, Jessell TM, Woolf CJ, Ma Q (2006) Runx1 determines nociceptive sensory neuron phenotype and is required for thermal and neuropathic pain. Neuron 49:365-377.

Cheng L, Arata A, Mizuguchi R, Qian Y, Karunaratne A, Gray PA, Arata S, Shirasawa S, Bouchard M, Luo P, Chen CL, Busslinger M, Goulding M, Onimaru H, Ma Q (2004) Tlx3 and Tlx1 are post-mitotic selector genes determining glutamatergic over GABAergic cell fates. Nat Neurosci 7:510-517.

Cheng L, Samad OA, Xu Y, Mizuguchi R, Luo P, Shirasawa S, Goulding M, Ma Q (2005) Lbx1 and Tlx3 are opposing switches in determining GABAergic versus glutamatergic transmitter phenotypes. Nat Neurosci 8:1510-1515.

Danielian PS, Muccino D, Rowitch DH, Michael SK, McMahon AP (1998) Modification of gene activity in mouse embryos in utero by a tamoxifeninducible form of Cre recombinase. Curr Biol 8:1323-1326.

Dykes IM, Lanier J, Eng SR, Turner EE (2010) Brn3a regulates neuronal subtype specification in the trigeminal ganglion by promoting Runx expression during sensory differentiation. Neural Dev 5:3.

Dykes IM, Tempest L, Lee SI, Turner EE (2011) Brn3a and Isletl act epistatically to regulate the gene expression program of sensory differentiation. J Neurosci 31:9789-9799.

Eng SR, Lanier J, Fedtsova N, Turner EE (2004) Coordinated regulation of gene expression by Brn3a in developing sensory ganglia. Development 131:3859-3870.

Gross MK, Dottori M, Goulding M (2002) Lbx1 specifies somatosensory association interneurons in the dorsal spinal cord. Neuron 34:535-549.

Growney JD, Shigematsu H, Li Z, Lee BH, Adelsperger J, Rowan R, Curley DP, Kutok JL, Akashi K, Williams IR, Speck NA, Gilliland DG (2005) Loss of Runx1 perturbs adult hematopoiesis and is associated with a myeloproliferative phenotype. Blood 106:494-504.

Huang EJ, Zang K, Schmidt A, Saulys A, Xiang M, Reichardt LF (1999) POU domain factor Brn-3a controls the differentiation and survival of trigeminal neurons by regulating Trk receptor expression. Development 126:2869-2882.

Imamachi N, Park GH, Lee H, Anderson DJ, Simon MI, Basbaum AI, Han SK (2009) TRPV1-expressing primary afferents generate behavioral responses to pruritogens via multiple mechanisms. Proc Natl Acad Sci U S A 106:11330-11335.
Kiasalari Z, Salehi I, Zhong Y, McMahon SB, Michael-Titus AT, Michael GJ (2010) Identification of perineal sensory neurons activated by innocuous heat. J Comp Neurol 518:137-162.

Lagerström MC, Rogoz K, Abrahamsen B, Persson E, Reinius B, Nordenankar K, Olund C, Smith C, Mendez JA, Chen ZF, Wood JN, Wallén-Mackenzie A, Kullander K (2010) VGLUT2-dependent sensory neurons in the TRPV1 population regulate pain and itch. Neuron 68:529-542.

Lallemend F, Ernfors P (2012) Molecular interactions underlying the specification of sensory neurons. Trends Neurosci 35:373-381.

Lanier J, Dykes IM, Nissen S, Eng SR, Turner EE (2009) Brn3a regulates the transition from neurogenesis to terminal differentiation and represses non-neural gene expression in the trigeminal ganglion. Dev Dyn 238:3065-3079.

Lei L, Zhou J, Lin L, Parada LF (2006) Brn3a and Klf7 cooperate to control TrkA expression in sensory neurons. Dev Biol 300:758-769.

Li MZ, Wang JS, Jiang DJ, Xiang CX, Wang FY, Zhang KH, Williams PR, Chen ZF (2006) Molecular mapping of developing dorsal hornenriched genes by microarray and dorsal/ventral subtractive screening. Dev Biol 292:555-564.

Liu P, Jenkins NA, Copeland NG (2003) A highly efficient recombineeringbased method for generating conditional knockout mutations. Genome Res 13:476-484.

Liu Q, Vrontou S, Rice FL, Zylka MJ, Dong X, Anderson DJ (2007) Molecular genetic visualization of a rare subset of unmyelinated sensory neurons that may detect gentle touch. Nat Neurosci 10:946-948.

Liu Q, Tang Z, Surdenikova L, Kim S, Patel KN, Kim A, Ru F, Guan Y, Weng HJ, Geng Y, Undem BJ, Kollarik M, Chen ZF, Anderson DJ, Dong X (2009) Sensory neuron-specific GPCR Mrgprs are itch receptors mediating chloroquine-induced pruritus. Cell 139:1353-1365.

Liu Y, Ma Q (2011) Generation of somatic sensory neuron diversity and implications on sensory coding. Curr Opin Neurobiol 21:52-60.

Liu Y, Yang FC, Okuda T, Dong X, Zylka MJ, Chen CL, Anderson DJ, Kuner $\mathrm{R}, \mathrm{Ma} \mathrm{Q}$ (2008) Mechanisms of compartmentalized expression of Mrg class G-protein-coupled sensory receptors. J Neurosci 28:125-132.

Liu Y, Abdel Samad O, Duan B, Zhang L, Tong Q, Lopes C, Ji RR, Lowell B, Ma Q (2010) VGLUT2-dependent glutamate release from peripheral nociceptors is required to sense pain and suppress itch. Neuron 68:543-556.

Luo W, Wickramasinghe SR, Savitt JM, Griffin JW, Dawson TM, Ginty DD (2007) A hierarchical NGF signaling cascade controls Ret-dependent and Ret-independent events during development of nonpeptidergic DRG neurons. Neuron 54:739-754.

Ma L, Lei L, Eng SR, Turner E, Parada LF (2003) ). Brn3a regulation of TrkA/NGF receptor expression in developing sensory neurons. Development 130:3525-3534.

Ma Q, Chen Z, del Barco Barrantes I, de la Pompa JL, Anderson DJ (1998) neurogenin 1 is essential for the determination of neuronal precursors for proximal cranial sensory ganglia. Neuron 20:469-482.

Ma Q, Fode C, Guillemot F, Anderson DJ (1999) Neurogenin1 and neurogenin2 control two distinct waves of neurogenesis in developing dorsal root ganglia. Genes Dev 13:1717-1728.

Maier H, Ostraat R, Gao H, Fields S, Shinton SA, Medina KL, Ikawa T, Murre C, Singh H, Hardy RR, Hagman J (2004) Early B cell factor cooperates with Runxl and mediates epigenetic changes associated with mb-1 transcription. Nat Immunol 5:1069-1077.

Molliver DC, Wright DE, Leitner ML, Parsadanian AS, Doster K, Wen D, Yan Q, Snider WD (1997) IB4-binding DRG neurons switch from NGF to GDNF dependence in early postnatal life. Neuron 19:849-861.

Morgan BA, Fekete DM (1996) Manipulating gene expression with replication-competent retroviruses. Methods Cell Biol 51:185-218.

Müller T, Brohmann H, Pierani A, Heppenstall PA, Lewin GR, Jessell TM, Birchmeier C (2002) The homeodomain factor Lbx1 distinguishes two major programs of neuronal differentiation in the dorsal spinal cord. Neuron 34:551-562.

Patel KN, Dong X (2011) Itch: cells, molecules, and circuits. ACS Chem Neurosci 2:17-25.

Qian Y, Fritzsch B, Shirasawa S, Chen CL, Choi Y, Ma Q (2001) Formation of brainstem (nor)adrenergic centers and first-order relay visceral sensory neurons is dependent on homeodomain protein Rnx/Tlx3. Genes Dev 15:2533-2545.

Qian Y, Shirasawa S, Chen CL, Cheng L, Ma Q (2002) Proper development 
of relay somatic sensory neurons and D2/D4 interneurons requires homeobox genes $R n x / T l x 3$ and Tlx1. Genes Dev 16:1220-1233.

Rau KK, McIlwrath SL, Wang H, Lawson JJ, Jankowski MP, Zylka MJ, Anderson DJ, Koerber HR (2009) Mrgprd enhances excitability in specific populations of cutaneous murine polymodal nociceptors. J Neurosci 29:8612-8619.

Rodríguez CI, Buchholz F, Galloway J, Sequerra R, Kasper J, Ayala R, Stewart AF, Dymecki SM (2000) High-efficiency deleter mice show that FLPe is an alternative to Cre-loxP. Nat Genet 25:139-140.

Shim WS, Oh U (2008) Histamine-induced itch and its relationship with pain. Mol Pain 4:29.

Shirasawa S, Arata A, Onimaru H, Roth KA, Brown GA, Horning S, Arata S, Okumura K, Sasazuki T, Korsmeyer SJ (2000) ). Rnx deficiency results in congenital central hypoventilation. Nat Genet 24:287-290.

Snider WD, McMahon SB (1998) Tackling pain at the source: new ideas about nociceptors Neuron 20:629-632.

Sun Y, Dykes IM, Liang X, Eng SR, Evans SM, Turner EE (2008) A central role for Islet1 in sensory neuron development linking sensory and spinal gene regulatory programs. Nat Neurosci 11:1283-1293.

Wilson SR, Gerhold KA, Bifolck-Fisher A, Liu Q, Patel KN, Dong X,
Bautista DM (2011) TRPA1 is required for histamine-independent, Mas-related G protein-coupled receptor-mediated itch. Nat Neurosci 14:595-602.

Woolf CJ, Ma Q (2007) Nociceptors-noxious stimulus detectors. Neuron 55:353-364.

Xu Y, Lopes C, Qian Y, Liu Y, Cheng L, Goulding M, Turner EE, Lima D, Ma Q (2008) Tlx1 and Tlx3 coordinate specification of dorsal horn painmodulatory peptidergic neurons. J Neurosci 28:4037-4046.

Yoshikawa M, Senzaki K, Yokomizo T, Takahashi S, Ozaki S, Shiga T (2007) Runxl selectively regulates cell fate specification and axonal projections of dorsal root ganglion neurons. Dev Biol 303:663-674.

Yoshimura M, Jessell T (1990) Amino acid-mediated EPSPs at primary afferent synapses with substantia gelatinosa neurones in the rat spinal cord. J Physiol 430:315-335.

Zou M, Li S, Klein WH, Xiang M (2012) Brn3a/Pou4f1 regulates dorsal root ganglion sensory neuron specification and axonal projection into the spinal cord. Dev Biol 364:114-127.

Zylka MJ, Rice FL, Anderson DJ (2005) Topographically distinct epidermal nociceptive circuits revealed by axonal tracers targeted to Mrgprd. Neuron 45:17-25. 